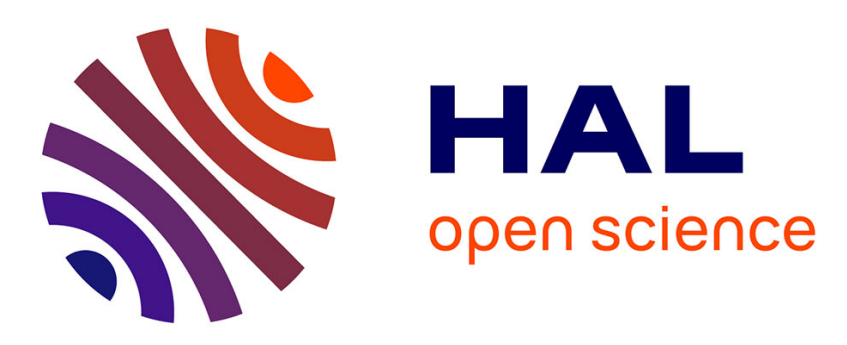

\title{
The male external urethral sphincter is autonomically innervated
}

Krystel Nyangoh Timoh, David Moszkowicz, M Creze, M Zaitouna, Margaux

Felber, Cédric Lebacle, Djibril Diallo, Jelena Martinovic, Ashutosh Tewari, Vincent Lavoué, et al.

\section{To cite this version:}

Krystel Nyangoh Timoh, David Moszkowicz, M Creze, M Zaitouna, Margaux Felber, et al.. The male external urethral sphincter is autonomically innervated. Clinical Anatomy, 2021, 34 (2), pp.263-271. 10.1002/ca.23698 . hal-03001375

\section{HAL Id: hal-03001375 https://hal.science/hal-03001375}

Submitted on 20 Nov 2020

HAL is a multi-disciplinary open access archive for the deposit and dissemination of scientific research documents, whether they are published or not. The documents may come from teaching and research institutions in France or abroad, or from public or private research centers.
L'archive ouverte pluridisciplinaire HAL, est destinée au dépôt et à la diffusion de documents scientifiques de niveau recherche, publiés ou non, émanant des établissements d'enseignement et de recherche français ou étrangers, des laboratoires publics ou privés. 


\section{The male external urethral sphincter is autonomically innervated}

Krystel Nyangoh Timoh ${ }^{1,2}$, David Moszkowicz ${ }^{1}$, Maud Creze ${ }^{1}$, Mazen Zaitouna ${ }^{1}$, Margaux Felber $^{1}$, Cédric Lebacle ${ }^{1,3}$, Djibril Diallo ${ }^{1}$, Jelena Martinovic ${ }^{4}$, Ashutosh Tewari ${ }^{5}$, Vincent Lavoué $^{2}$, Gevorg Ghukasyan ${ }^{6}$, Gerard Benoit ${ }^{1}$, Thomas Bessede ${ }^{1,3}$.

\section{Affiliations}

${ }^{1}$ UMR 1195, University Paris Sud, INSERM, Université Paris-Saclay, 94270, Le KremlinBicetre, France

${ }^{2}$ Department of Obstetrics and Gynecology, Hopital Universitaire de Rennes, university Rennes 1, Rennes, France.

${ }^{3}$ Urology Department, Hopitaux Universitaires Paris-Sud, APHP, 94270, Le Kremlin-Bicetre, France

${ }^{4}$ Department of Fetal Pathology, Hopitaux universitaires Paris-Sud, APHP, 92140, Clamart, France

${ }^{5}$ Department of Urology, Icahn School of Medicine at Mount Sinai, New York, NY, USA.

${ }^{6}$ Université de Rennes 1, Rennes, France; INSERM, UMR991 Liver Metabolism and Cancer, Rennes, France.

\section{Corresponding author:}

Krystel NYANGOH TIMOH, MD.

INSERM-UMR 1195 Hôpital de Bicêtre, Bâtiment Grégory Pincus, 80 rue du Général Leclerc, 94276 Le Kremlin-Bicêtre Cedex, France

Tel: 0331495918 83; E-mail: k.nyangoh@gmail.com

The study was approved by the French Biomedicine Agency (PFS15-011). 


\section{Abstract:}

Introduction: The aim of the present study was to describe autonomic urethral sphincter (US) innervation using specific muscular and neuronal antibody markers and 3D reconstruction.

Material and Methods: We performed en-bloc removal of the entire pelvis of three male human fetuses between 18 and 40 weeks.

Serial whole mount sections ( $5 \mu \mathrm{m}$ intervals) were stained and investigated. The sections were stained with Masson's trichrome and Eosin Hematoxylin, and immunostained with: antiSMA antibody for smooth muscle; anti-S100 antibody for all nerves; and anti-PMP22 antibody, anti-TH antibody, anti-CGRP antibody, anti-NOS antibody for somatic, adrenergic, sensory and nitrergic nerve fibers, respectively. The slides were digitized for 3D reconstruction to improve topographical understanding. An animated reconstruction of the autonomic innervation of the US was generated.

Results: The external and internal US are innervated by autonomic nerves of the inferior hypogastric plexus (IHP). These nerves are sympathetic (positive anti-TH antibody), sensory (positive anti-CGRP antibody), and nitrergic (positive anti-NOS antibody). Some autonomic fibers run within the neurovascular bundles, posterolaterally. Others run from the IHP to the posteromedial aspect of the prostate apex, above an through the rectourethral muscle. The external US is also innervated by somatic nerves (positive anti-PMP22 antibody) arising from the pudendal nerve, joining the midline but remaining below the rectourethral.

Conclusions: This study provides anatomical evidence of an autonomic component in the innervation of the external US that travels in the neurovascular bundle. During radical prostatectomy, the rectourethral muscle and the neurovascular bundles are to be preserved, particularly during apical dissection.

Key words : anatomy- innervation- urethral sphincter- prostate-neurovascular bundlesincontinence 


\section{Introduction}

Radical prostatectomy is responsible for erectile dysfunction in around 10 to $46 \%$ of patients and for urinary incontinence in around 16\% (Ficarra et al., 2012a; Ficarra et al., 2012b) .With a view to improving postoperative erectile function Walsh described a nerve-sparing radical prostatectomy procedure aimed at preserving the neurovascular bundles (NVB) (Walsh and Donker, 2017). Furthermore, several recent clinical studies suggest that preservation of the NVB is associated with improved postoperative urinary continence after radical prostatectomy (Reeves et al., 2015) (Srivastava et al., 2013 ; Steineck et al., 2015). Postoperative urinary continence is multifactorial, but the urethral sphincter (US), and in particular the external US (EUS), are major actors of urinary continence (Bessede et al., 2017). It has previously been suggested that the autonomic supply for the US is similar to the neural pathway of the erectile bodies (Hinata et al., 2014), however anatomical evidence based on specific neuronal markers is lacking. Classically, autonomic nerves are described to run above the levator ani muscle while somatic nerves run below. In a previous study using immunohistochemistry and three-dimensional reconstruction, our team described the innervation of the medial part of the levator ani muscle by autonomic nerves (Nyangoh Timoh et al., 2017).

Therefore, we hypothesized that the EUS innervation, is supplied by autonomic innervation using the same pathway that NVB.

The aim of the present study was to describe autonomic US innervation using specific muscular and neuronal antibody markers and 3D reconstruction. 


\section{Material and Methods}

\section{Human fetuses}

The fetal specimens were obtained from late miscarriages. All parents gave written consent and authorization for the scientific use of the cadaver. Only specimens without maceration and without morphological or neurological macroscopic abnormalities on pathology examination were used.

The study was approved by the French Biomedicine Agency (PFS15-011).

Three human male fetuses had a gestational age of between 18 and 40 weeks.

\section{Macroscopic dissection}

The entire pelvis was removed en-bloc with the pelvic organ and pelvic bone, and was fixed in formalin ( $10 \%$ formaldehyde) for $48 \mathrm{~h}$. Tissues were then cut into transverse or sagittal slices at 4-mm intervals. The tissue slices were placed in baskets, processed, and embedded in cardboard molds filled with paraffin. Slices were kept warm in water at $37^{\circ} \mathrm{C}$ and then mounted whole on Superfrost glass slides. They were then dried at $37^{\circ} \mathrm{C}$ overnight. Series of $5 \mu \mathrm{m}$-thick sections were subsequently created without intervals.

Staining and immunolabeling (Supporting information 1: Table 1).

The first section of each level was taken as the reference and was stained with Masson's trichrome or eosin and hematoxylin to provide information about the topography of anatomical structures. Smooth muscles were detected with polyclonal antibodies against alpha-smooth muscle actin (SMA).

Neuronal markers were detected with polyclonal antibodies against protein S100 (PS100) for labeling all nerves, peripheral myelin protein (PMP 22) for the somatic peripheral nervous system, tyrosine hydroxylase (TH) for adrenergic nerves, the neural isoform of nitric oxide synthase (nNOS) for the pro-erectile nerve bundles, and the calcitonin gene-related peptide (CGRP) for primary sensory neuropeptide immunolabeling (Moszkowicz et al., 2011) .

The avidin-biotin-peroxidase detection procedure was carried out with a Vectastain ABC kit (ref. PK6100; Vector Laboratories, Burlingame, CA, USA). Chromogenic detection was performed with a DAB detection kit (DAB, ref. SK-4100; Vector Laboratories). Non-immune serum or IgG at an equivalent dilution was used as a control for all the immunohistochemical analyses.

\section{Histological examination}


Serial stained and immunolabeled two-dimensional (2D) sections were used for threedimensional (3D) reconstruction. Using high magnification ( $4 \times$ to $40 \times$ ) analyses of the Masson's trichrome and eosin and hematoxylin-stained sections, it was possible to identify the various anatomical structures. Subsequent sections, treated with an antibody against S100, were used to identify pelviperineal nerves. By comparing the Masson's trichrome-stained sections with sections stained with specific antibodies against SMA, S100, TH, PMP22, CGRP and nNOS, it was possible to determine the structure of muscle (smooth (SMA)) and the nature of the nerve fibers identified: i.e., somatic (PMP22), autonomic (TH), sensory (CGRP) or nitrergic (nNOS).

The sections were taken at almost the same level with a negligible interval between sections $(5 \mu \mathrm{m})$. The computer system comprised a personal laptop computer (Windows XP) equipped with an Epson Perfection V750 digitization system, Silverfast AI digitization software, Adobe Photoshop image-processing software, and Surfdriver software for Windows (Winsurf image reconstruction software, version 4.3). All sections were digitized at a resolution of 4800 dots per inch, and the images were then stacked and aligned. The pelvic anatomical structures and nerve fibers were outlined manually on all histological sections. A $3 \mathrm{D}$ analysis of the location, course, and distribution of the nerve fibers and muscle structure was then carried out. An animated reconstruction was generated (Supporting information 2). 


\section{Results}

\section{Global morphology of the urethral sphincter (US)}

The US is composed of a deep internal smooth muscle layer and a superficial external striated muscle layer.

\section{External US (EUS)}

The EUS contains striated muscle cells only. It is circular, completely surrounds the urethra (Fig. 1B1, 1B2, 1B3 and supporting information 3), and is in continuation with the musculus vesicoprostaticus above (Fig. 1A1, 1A2, 1A3 and supporting information 3).

Cranially, the anterior wall of the EUS is thicker than its posterior wall with transversal sections showing a signet-ring appearance (Fig. 1B1, 1B2, and 1B3).

Caudally, and as it approaches the bulb of the penis, the posterior wall of the EUS thins and fades along the midline whereas it thickens into two pillars or wings laterally (Fig. 1C1, 1C2, 1C3 and supporting information 3). At this posterior opening of the EUS, glands, vessels and nerves penetrate into the US. This opening is also where the smooth muscle central compartment attaches to the IUS (Fig. 1C1, 1C2, 1C3 and Fig.4).

\section{Internal US (IUS)}

The IUS contains smooth muscle cells only. It is composed of three layers: a thin longitudinal superficial layer, a dense circular layer and a thin longitudinal deep layer (Fig. 1B1, 1B2, and 1B3). Franially, the IUS is in continuation with smooth muscle (anti-SMA positive) areas within the prostate that correspond to McNeal's zones: ventrally with the anterior fibromuscular stroma of the prostate, and dorsally with the peripheral zone of the prostate (Fig. 1B1, 1B2, 1B3, Fig. 3, Fig. 3B2 and 3B3).

Caudally, the posterior aspect of the IUS is attached to the smooth muscle central compartment (Fig. 2B1, and 2B2) and also receives nerves and vessels that reach the urethral wall or the cavernous and spongiosis corpus (Fig. 3D and Fig. 4). 


\section{Innervation of the US}

\section{Autonomic system}

Smooth muscle areas are innervated by nerves arising from the inferior hypogastric plexus (IHP). The IHP consists of hypogastric and pelvic splanchnic nerves. It is possible to distinguish retrorectal, laterorectal, interprostatorectal, lateroprostatic, and anteroprostatic fibers (Fig. 3A).

The distal part of the IHP is localized in a triangular zone between the levator ani muscle laterally, the urethra anteriorly and the rectum posteriorly. The nerves (S100 positive) are: sympathetic (antiTH positive), sensory (anti-CGRP positive), nitrergic (anti-NOS positive) (Fig. 3A, 3B, 3C, 3D, 3E, 3F and 3G). There are no somatic (anti-PMP22 negative) nerves (Fig. 4G).

Urethral innervation is supplied by lateroprostatic and prerectal nerve fibers all of which pass through the rectourethral muscle between the rectum and the urethra (Fig. 5), and then through the middle of the US opening. Some fibers then penetrate the urethra along the midline in the ventral direction, while others curve around the bulb and penetrate the urethral wall at 3 and 9 o'clock (Fig. 4 and Fig. 5).

Nerve fibers spread into the EUS, the IUS and the urethral submucosa (Fig. 4). The autonomic system therefore innervates both the striated EUS and the smooth IUS.

The nitrergic fibers originate from the NVB and innervate the EUS and IUS. These fibers also supply innervation for the erectile bodies. (Fig. 4).

\section{Somatic system}

After branching off to form the dorsal nerve of the penis, the pudendal nerve (PN) gives nerve fibers that curve medially to the EUS at the level of the wings. These nerves are thus perineal and they penetrate the EUS at its posterior aspect. The nerves are somatic (anti-PMP22 positive). No somatic branches coming from pelvic nerves are observed for the EUS (Supporting information 4). 


\section{Discussion}

We demonstrate that both the EUS and IUS are innervated by autonomic and somatic nerves. The autonomic nerves supplying the urethra: 1) run within the NVB, and 2) arise from the IHP to run at the posteromedial aspect of the prostate apex and through the rectourethral muscle.

Human fetal material is a good model to study pelvic anatomy (Nyangoh Timoh et al., 2017; Nyangoh Timoh et al., 2018). First, the small size of fetus pelvis enables en-bloc removal and processing with mega-cassette embedding which limits data loss and structure displacement compared to surgical dissection. Therefore, the whole neuroanatomy and muscular pelvic floor anatomy is preserved. Second, the small size of the fetus pelvis also makes 3D reconstruction easier. Third, as the nerves are relatively larger in the fetus as opposed to the adult, the neuroanatomy is more easily visualized. Finally, the use of multiple specific muscular and neuronal markers is more feasible with fresh materials.

Numerous discrepancies exists about the involvement of autonomic nerves from the IHP to the EUS.

Classically, the striated muscle EUS is described as being innervated by somatic nerve fibers, and the smooth muscle IUS innervated by autonomic nerves (Srivastava et al., 2013; Strasser et al., 2000). However, our team has demonstrated: 1) the existence of autonomic (IHP) and somatic (PN) communications within the levator ani muscle (Alsaid et al., 2011), and 2) that the medial part of the levator ani muscle is innervated by nerves arising from the IHP (Nyangoh Timoh et al., 2017). In 1987, Kumagai already observed unmyelinated axons in the EUS (Kumagai et al., 1987). Some authors then went on to provide evidence of the involvement of pelvic branches for US innervation ¿sing conventional dissection. These pelvic branches were described as somatic nerves coming from the PN or from the nerve to the levator ani (Akita et al., 2003), or as autonomic nerves from the IHP (Hinata et al., 2014; Hollabaugh et al., 1997; Takenaka et al., 2005). Such controversy highlights the limitation of gross anatomy dissection studies in the field of nerve characterization (Bessede et al., 2017).

In the present study using specific neuronal markers, we observed autonomic nerves arising from the IHP and supplying innervation to the EUS. These findings are consistent with the study of Hinata et al. reporting the presence of NOS+ nerve fibers within the EUS (Hinata et al., 2014). Hinata concluded that the external US is innervated from the IHP (Hinata et al., 2014). Another controversy remains about the exact location of fibers that supply the US. In the present study, we observed that autonomic nerves supplying the US are located posterolaterally at midprostate, then shift to a posteromedial position to join the prostate apex, pass through the smooth rectourethral muscle, and innervate the US before ultimately continuing towards the erectile bodies. In past we have shown that peri prostatic nerves rather form a hammock and it converges in the 
midline near the apex (Tewari et al., 2011). Ganzer also observed pelvic nerves running towards the dorsal region of the EUS (Ganzer et al., 2015). This posteromedial position of autonomic nerves supplying the EUS represents a functional risk during apical dissection and the retrourethral detachment of rectourethral muscle fibers.

The classic anatomical description of the NVB indicates that they contain cavernous nerves which are located in the posterolateral aspect of the prostate. NVB are part of IHP. Recent studies have suggested that the cavernous nerves do not strictly follow the course of the NVB, do not form a fascicle and have a fan-like distribution at several levels (Alsaid et al., 2010; Costello et al., 2004; Takenaka et al., 2005). In the present study, we demonstrated that autonomic fibers from the NVB supply innervation to the EUS (Fig. 6A and 6B). This anatomical evidence underpins clinical observations that preserving the NVB may limit urinary incontinence (Reeves et al., 2015; Srivastava et al., 2013; Steineck et al., 2015).

The origin of the somatic control of the EUS is also a matter of debate. It has been reported that the pelvic somatic nerves supplying innervation to the EUS come from the intrapelvic PN and/or from the nerve to the levator ani (Hollabaugh et al., 1997). Using luxol fast blue, Karam observed intrapelvic supralevator somatic nerve fibers supplying the urethra (Karam et al., 2005). However, luxol fast blue is not as effective as neuronal markers. In the present study using antimyelin markers, we did not observe any somatic fibers within the IHP that would supply nerves to the EUS. However, we did observe an infralevator perineal branch coming from the PN and supplying the EUS. These findings are consistent with Strasser, Narayan, and Jueneman (Juenemann et al., 1988; Narayan et al., 1995; Strasser et al., 2000). Moreover, we located this perineal branch below the rectourethral muscle, which suggests that it is not in the surgical field of retropubic or laparoscopic radical prostatectomy. On the other hand, this somatic pathway is exposed during perineal prostatectomy.

From a physiopathological point of view, autonomic nerves in the EUS may help early return of urinary continence (Hinata et al., 2014). These branches also innervate the medial part of the levator ani muscle and the rectourethral muscle which may indicate a coordinating role. Moreover, the high density of sensory nerves is of major importance for the reflex activity of the EUS. Similarly, the high density of NOS fibers may help regulate striated muscle performance (Hinata et al., 2014). Autonomic nerves could also target the vessels rather than muscles and regulate blood flow.

From a clinical point of view, we can systematize three nerve pathways to the EUS: 1) autonomic nerves running within the NVB, 2) autonomic nerves running from the IHP to the posteromedial aspect of the prostate apex and remaining above and through the rectourethral muscle and, 3 ) somatic nerves arising from the PN, joining the midline but remaining below the rectourethral muscle (Fig. 6). As mentioned above, recent clinical studies suggest that preserving the NVB 
during surgery improves postoperative continence after radical prostatectomy (Reeves et al., 2015; Srivastava et al., 2013; Steineck et al., 2015). The present study provides anatomical evidence for this hypothesis. Using neuronal markers, we observed autonomic nerves, sympathetic, sensory and highly nitrergic coming from the IHP and supplying the urethra. These nerves also innervate and pass through the rectourethral muscle which should be considered as a structure to be preserved by a cautious peeling during the retroapical dissection. Ultimately, our results demonstrate that autonomic nerve fibers of the US are more exposed than its somatic fibers during retropubic or laparoscopic radical prostatectomy.

Despite these results, our study has some limitations.

Although the fetal model is a mature and established model for neuroanatomical study, its use can be criticized. However, at the end of the embryonic period, the pelvic anatomy is comparable to that in adults (Fritsch, 1989). Second, the small sample size could lead to bias. However, the same anatomic observations were established for the three fetuses. Moreover, the axis sections were different (axial and sagittal) so as to provide several views. Third, it may remain unclear if nerve anatomical localization have functional relevance. However, in the present study, the use of neuronal antibodies helps to understand nerve function. Finally, the absence of a somatic intrapelvic branch may be related to the fact that myelinization is a late event during fetal development. However, we were able to identify the somatic control of the EUS coming from perineal branch of PN. Moreover, as the total pelvis was removed en-bloc and we took continuous serial sections at $4 \mu \mathrm{m}$ intervals, we were able to strictly follow the course of the nerves.

\section{Conclusion}

This study provides anatomical evidence of an autonomic component in the innervation of the external US that travels in the neurovascular bundle. During radical prostatectomy, the rectourethral muscle and the neurovascular bundles are to be preserved, particularly during apical dissection.

\section{Acknowledgement section}

The authors sincerely thank those who donated their bodies to science so that anatomical research could be performed. Results from such research can potentially increase mankind's overall knowledge that can then improve patient care. Therefore, these donors and their families deserve our highest gratitude. 
References

Akita K, Sakamoto H \& Sato T. (2003) Origins and courses of the nervous branches to the male urethral sphincter. Surgical and radiologic anatomy, 25:387-392.

Alsaid B, Karam I, Bessede T, Abdlsamad I, Uhl JF, Delmas V, Benoit G \& Droupy S. (2010).

Tridimensional computer-assisted anatomic dissection of posterolateral prostatic neurovascular bundles. European urology, 58:281-287.

Alsaid B, Moszkowicz D, Peschaud F, Bessede T, Zaitouna M, Karam I, Droupy S \&Benoit G. (2011). Autonomic-somatic communications in the human pelvis: computer-assisted anatomic dissection in male and female fetuses. Journal of anatomy, 219:565-573.

Bessede T, Sooriakumaran P, Takenaka A \&Tewari A. (2017). Neural supply of the male urethral sphincter: comprehensive anatomical review and implications for continence recovery after radical prostatectomy. World journal of urology, 35:549-565.

Costello AJ, Brooks M \&Cole OJ. (2004). Anatomical studies of the neurovascular bundle and cavernosal nerves. BJU international, 94:1071-1076.

Ficarra V, Novara G, Ahlering TE, Costello A, Eastham JA, Graefen M, Guazzoni G, Menon M, Mottrie A, Patel VR, Van der Poel H, Rosen RC, Tewari AK, Wilson TG, Zattoni F \& Montorsi F. (2012a). Systematic review and meta-analysis of studies reporting potency rates after robot-assisted radical prostatectomy. European urology, 62:418-430.

Ficarra V, Novara G, Rosen RC, Artibani W, Carroll PR, Costello A, Menon M, Montorsi F, Patel VR, Stolzenburg JU, Van der Poel H, Wilson TG, Zattoni F \& Mottrie A. (2012b). Systematic review and meta-analysis of studies reporting urinary continence recovery after robotassisted radical prostatectomy. European urology, 62:405-417.

Fritsch H. (1989). Topography of the pelvic autonomic nerves in human fetuses between 21-29 weeks of gestation. Anatomy and embryology,180:57-64.

Ganzer R, Stolzenburg JU, Neuhaus J, Weber F, Fuchshofer R, Burger M \& Brundl J. (2015). Anatomical study of pelvic nerves in relation to seminal vesicles, prostate and urethral sphincter: immunohistochemical staining, computerized planimetry and 3-dimensional reconstruction. The Journal of urology,193:1205-1212.

Hinata N, Murakami G, Miyake H, Tanaka K, Abe S, Fujimiya M, Takenaka A \&Fujisawa M. (2014). Urethral sphincter fatigue after robot-assisted radical prostatectomy: descriptive questionnaire-based study and anatomic basis. Urology, 84:144-148.

Hollabaugh RS, Jr., Dmochowski RR \& Steiner MS. (1997). Neuroanatomy of the male rhabdosphincter. Urology, 49:426-434.

Juenemann KP, Lue TF, Schmidt RA \&Tanagho EA. (1988). Clinical significance of sacral and pudendal nerve anatomy. The Journal of urology, 139:74-80.

Karam I, Droupy S, Abd-Alsamad I, Korbage A, Uhl JF, Benoit G \&Delmas V. (2005). The precise location and nature of the nerves to the male human urethra: histological and immunohistochemical studies with three-dimensional reconstruction. European urology, 48:858-864.

Kumagai A, Koyanagi T \&Takahashi Y. (1987). The innervation of the external urethral sphincter; an ultrastructural study in male human subjects. Urological research, 15:39-43.

Moszkowicz D, Alsaid B, Bessede T, Zaitouna M, Penna C, Benoit G \&Peschaud F. (2011). Neural supply to the clitoris: immunohistochemical study with three-dimensional reconstruction of cavernous nerve, spongious nerve, and dorsal clitoris nerve in human fetus. The journal of sexual medicine, 8:1112-1122.

Narayan P, Konety B, Aslam K, Aboseif S, Blumenfeld W \& Tanagho E. (1995). Neuroanatomy of the external urethral sphincter: implications for urinary continence preservation during radical prostate surgery. The Journal of urology, 153:337-341.

Nyangoh Timoh K, Bessede T, Lebacle C, Zaitouna M, Martinovic J, Diallo D, Creze M, Chevallier JM, Darai E, Benoit G \&Moszkowicz D. (2017). Levator ani muscle innervation: Anatomical study in human fetus. Neurourology and urodynamics, 36:1464-1471.

Nyangoh Timoh K, Moszkowicz D, Zaitouna M, Lebacle C, Martinovic J, Diallo D, Creze M, Lavoue V, Darai E, Benoit G \&Bessede T. (2018). Detailed muscular structure and neural control anatomy of the levator ani muscle: a study based on female human fetuses. American journal of obstetrics and gynecology, 218:121.e121-121.e112. 
Reeves F, Preece P, Kapoor J, Everaerts W, Murphy DG, Corcoran NM \&Costello AJ. (2015). Preservation of the neurovascular bundles is associated with improved time to continence after radical prostatectomy but not long-term continence rates: results of a systematic review and meta-analysis. European urology, 68:692-704.

Srivastava A, Chopra S, Pham A, Sooriakumaran P, Durand M, Chughtai B, Gruschow S, Peyser A, Harneja N, Leung R, Lee R, Herman M, Robinson B, Shevchuk M \&Tewari A. (2013). Effect of a risk-stratified grade of nerve-sparing technique on early return of continence after robot-assisted laparoscopic radical prostatectomy. European urology, 63:438-444.

Steineck G, Bjartell A, Hugosson J, Axen E, Carlsson S, Stranne J, Wallerstedt A, Persson J, Wilderang U, Thorsteinsdottir T, Gustafsson O, Lagerkvist M, Jiborn T, Haglind E \& Wiklund P. (2015). Degree of preservation of the neurovascular bundles during radical prostatectomy and urinary continence 1 year after surgery. European urology, 67:559-568.

Strasser H, Ninkovic M, Hess M, Bartsch G \&Stenzl A. (2000). Anatomic and functional studies of the male and female urethral sphincter. World journal of urology, 18:324-329.

Takenaka A, Murakami G, Matsubara A, Han SH \&Fujisawa M. (2005). Variation in course of cavernous nerve with special reference to details of topographic relationships near prostatic apex: histologic study using male cadavers. Urology, 65:136-142.

Tewari AK, Srivastava A, Huang MW, Robinson BD, Shevchuk MM, Durand M, Sooriakumaran P, Grover S, Yadav R, Mishra N, Mohan S, Brooks DC, Shaikh N, Khanna A \&Leung R. (2011). Anatomical grades of nerve sparing: a risk-stratified approach to neural-hammock sparing during robot-assisted radical prostatectomy (RARP). BJU international, 108:984992.

Walsh PC \& Donker PJ. (2017). Impotence Following Radical Prostatectomy: Insight into Etiology and Prevention. The Journal of urology, 197:S165-s170. 


\section{Figure legends}

Figure 1: Serial transverse sections of a 21-week-old male fetus scanned at an optical resolution of $4800 \mathrm{dpi}$, at the levels of: prostate apex (A, A1, A2, A3), cranial membranous urethra (B, B1, B2, B3) and caudal membranous urethra (C, C1, C2, C3).

Prostate apex: (A, A1) Transverse section stained with eosin and hematoxylin. (A2) (A3) Transverse section stained with anti-SMA antibody. (A3) is the same section than (A2) with legends.

The prostate apex is sectioned with the anterior fibromuscular stroma of the prostate (anti-SMA positive, dark green area), transitional zone (dark blue) and the musculus vesicoprostaticus above (anti-SMA negative, dark red area).

Cranial membranous urethra : (B,B1) Transverse section stained with Hematoxylin's eosin. (B2) (B3) Transverse section stained with anti-SMA antibody. (B3) is the same section than (B2) with legends.

The EUS (light purple, anti-SMA negative) is circular, completely surrounds the urethra and is in ontinuation with the musculus vesicoprostaticus above.

The internal US (dark purple, anti-SMA positive) is composed of three layers: from superficial to deep: a thin longitudinal layer, a dense circular layer and another thin longitudinal layer. It continues with the anterior fibromuscular stroma of the prostate ventrally, and dorsally with the peripheral zone of the prostate.

Caudal membranous urethra: (C,C1) Transverse section stained with Masson's Trichrome. (C2) (C3) Transverse section stained with anti-SMA antibody. (C3) is the same section than (C2) with legends .

Caudally the posterior wall of the external US thickens into 2 pillars posterolaterally. This opening allows attachment of the smooth muscle central compartment to the internal US. 
Color code: Urethra (Ur, yellow), prostate with the anterior fibromuscular stroma of the prostate (AFMS, dark green area) transitional zone (TZ, dark blue) and the musculus vesicoprostaticus above (MVP, dark red area).

internal urethral sphincter (IUS, dark purple), external urethral sphincter (EUS, light purple), levator ani muscle (LAM, orange), rectum (beige), smooth muscle cells of the middle compartment (SMMC) with the core (or rectourethral muscle, light green), the endolevator area (or medial part of the levator ani, endo, pink). 
Figure 2: Sagittal (A, B, C) and parasagittal (D, E, F) sections of a 21-week-old male fetus scanned at an optical resolution of $\mathbf{4 8 0 0} \mathrm{dpi}$.

Sagittal: Sections are stained with hematoxylin and eosin (A), anti-SMA antibody (A1 and A2). (A2) is the same section than (A1) with legends.

External US continues the musculus vesicoprostaticus (anti-SMA negative, dark red area) above. Internal US continues with smooth muscle (ant-SMA positive) areas within the prostate.

Parasagittal: Sections are stained with Masson's trichrome (B), anti-SMA antibody (B1 and B2). (B2) is the same section than (B1) with legends.

The posterior aspect of the internal US (dark purple) receives smooth muscle cells from the smooth muscle of the middle compartment (infralevator area, light blue, anti-SMA positive).

Color code: prostate with the anterior fibromuscular stroma of the prostate (AFMS, dark green area) transitional zone (TZ, dark blue), central zone (ZC, light red) and the musculus vesicoprostaticus above (MVP, dark red area), external urethral sphincter (EUS, light purple), internal urethral sphincter (IUS, dark purple), levator ani muscle (LAM, orange), rectum (beige), smooth muscle cells of the middle compartment (infra levator area, light blue), obturator internal muscle (OIM, brown). 
Figure 3: Sagittal sections of a 21-week-old male fetus scanned at an optical resolution of 4800

dpi.

$\mathrm{ABCD}$

(A) Transversal section showing nerves localization of the inferior hypogastric plexus (IHP).

(B) Sagittal section stained with anti-S100 antibody

(B1) Sagittal section stained with hematoxylin and eosin

(B2, B3) Sagittal sections stained with anti-SMA antibody

(B3) is the same section than (B2) with legends.

The posterior aspect of the internal US (light purple) smooth muscle cells from the smooth muscle of the middle compartment (infralevator area, light blue, anti-SMA positive).

$(\mathrm{C}, \mathrm{D}, \mathrm{E}, \mathrm{F}, \mathrm{G})$ are magnified views from rectangle in $(\mathrm{B})$ with various staining.

All the nerves (anti-S100 positive, fig. B) are: sympathetic (anti-TH positive, fig. D), nitrergic (antiNOS positive, Fig. E) and sensory (anti-CGRP positive, Fig. G). They are not somatic (anti-PMP22 negative, Fig. G).

Staining positivity is shown by arrowheads.

Color code: prostate with the anterior fibromuscular stroma of the prostate (AFMS, dark green area) transitional zone (TZ, dark blue), central zone (ZC, light red) and the musculus vesicoprostaticus above (MVP, dark red area), external urethral sphincter (EUS, light purple), internal urethral sphincter (IUS, dark purple), levator ani muscle (LAM, orange), rectum (beige), smooth muscle cells of the middle compartment (infra levator area, light blue), obturator internal muscle (OIM, brown).

(B3) and (C) demonstrate that autonomic nerves travel through the smooth muscle of the middle compartment (SMMC) to innervate the external US. 
Figure 4: Transverse sections of a 21-week-old male fetus scanned at an optical resolution of 4800 dpi at the levels of: cranial membranous urethra (A, A1, A2) and caudal membranous urethra (B, B1, B2):

Sections (A) and (B) are stained with hematoxylin and eosin.

Sections (A1) and (B1) are stained with anti-S100 antibody. Sections (A2) and (B2) are stained with anti-NOS antibody.

Nerves for the urethra pass through the smooth muscle of the middle compartment (yellow

arrowhead) between the rectum and the urethra. Some fibers penetrate the urethra at 3 and 9 o'clock whereas others penetrate the midline in the ventral direction.

Pudendal nerve is shown with green arrowhead.

Nerve fibers spread into the external US, the internal US and the urethral submucosa.

The nitrergic nerves (anti-NOS positive) coming from the inferior hypogastric plexus (IHP) (black arrowhead) innervate the external and the internal US and also supply innervation for the erectile bodies.

Color code: External urethral sphincter (EUS, light purple), internal urethral sphincter (IUS, dark purple), levator ani muscle (LAM, orange), rectum (beige), smooth muscle cells of the middle compartment (the core or rectourethral muscle in green, endolevator area or medial part of the levator ani muscle in pink and infralevator area or deep transverse perineal muscle, light blue), and cavernous corpus $(\mathrm{CC}$, red). 
Figure 5: Computer-assisted anatomical dissection (CAAD) of the pelvic structure in a 21week-old male fetus:

(A) Right lateral views.

(B, C, D, E) Superior views. Nerves for the urethra are lateroprostatic and prerectal. They are localized in a triangular zone between urethra, rectum and levator ani muscle. All of the urethral fibers pass through a smooth muscle area (smooth muscle cell compartment) between the rectum and the urethra.

Nerves penetrate the urethra at 3 and 9 o'clock or on the midline in the ventral direction.

Some nerves come from the neurovascular bundles and innervate the external and the internal US and the erectile bodies

Urethra (yellow), prostate (dark red), internal urethral sphincter (dark purple), external urethral sphincter (dark purple), levator ani muscle (LAM, orange), rectum (beige), smooth muscle cell compartment (the core or rectourethral muscle in green, endolevator area or medial part of the levator ani muscle in pink and infralevator area or deep transverse perineal muscle, light blue), external anal sphincter (EAS, dark blue), plexus hypogastric ( yellow fibers).

Figure 6: The three nerve pathways of the External Urethral Sphincter innervation. 
Supporting information 1: Table

\begin{tabular}{|c|c|c|c|c|c|c|c|c|}
\hline $\begin{array}{l}\text { Antigen } \\
\text { (abbreviation) }\end{array}$ & Code & Tissue target & $\begin{array}{l}\text { Antigen } \\
\text { retrieval }\end{array}$ & $\begin{array}{l}\text { Incuba- } \\
\text { tion }\end{array}$ & $\begin{array}{l}\text { Positive } \\
\text { Control }\end{array}$ & Species & Dilution & Provider \\
\hline $\begin{array}{l}\text { Protein S100 } \\
\text { (PS100) }\end{array}$ & Z0311 & All nerves & no & $1 \mathrm{~h}$ & $\begin{array}{l}\text { Sacral } \\
\text { plexus }\end{array}$ & rabbit & $1 / 400$ & $\begin{array}{l}\text { Dako; } \\
\text { Denmark }\end{array}$ \\
\hline $\begin{array}{l}\text { calcitonin } \\
\text { gene related } \\
\text { peptide } \\
(\mathrm{CGRP})\end{array}$ & $\begin{array}{l}03- \\
16008\end{array}$ & $\begin{array}{l}\text { Sensory } \\
\text { nerves }\end{array}$ & $\begin{array}{l}\text { Citrate } \\
\text { buffer }\end{array}$ & $12 \mathrm{~h}$ & Human thyroid & rabbit & $1 / 200$ & $\begin{array}{l}\text { ARP, } \\
\text { American } \\
\text { research } \\
\text { products, } \\
\text { USA }\end{array}$ \\
\hline $\begin{array}{l}\text { Tyrosine } \\
\text { Hydroxylase } \\
\text { (TH) }\end{array}$ & ab112 & $\begin{array}{l}\text { Autonomic } \\
\text { Sympathetic } \\
\text { nerves }\end{array}$ & $\begin{array}{l}\text { Citrate } \\
\text { buffer }\end{array}$ & $12 \mathrm{~h}$ & $\begin{array}{l}\text { Suprare } \\
\text { nal } \\
\text { gland }\end{array}$ & rabbit & $1 / 750$ & $\begin{array}{l}\text { abcam; } \\
\text { USA }\end{array}$ \\
\hline $\begin{array}{l}\text { The neural } \\
\text { isoform of } \\
\text { nitric oxide } \\
\text { synthase } \\
\text { (nNOS) }\end{array}$ & 160870 & $\begin{array}{l}\text { Pro-erectile } \\
\text { nerves }\end{array}$ & no & $12 \mathrm{~h}$ & $\begin{array}{l}\text { Human adult } \\
\text { cavernous } \\
\text { nerve }\end{array}$ & rabbit & $1 / 200$ & $\begin{array}{l}\text { Cayman; } \\
\text { USA }\end{array}$ \\
\hline $\begin{array}{l}\text { Peripheral } \\
\text { Myelin } \\
\text { Protein (PMP } \\
22)\end{array}$ & ab61220 & $\begin{array}{l}\text { Somatic peripheral } \\
\text { nerves }\end{array}$ & no & $12 \mathrm{~h}$ & $\begin{array}{l}\text { Human } \\
\text { thyroid }\end{array}$ & rabbit & $1 / 100$ & abcam; USA \\
\hline $\begin{array}{l}\text { Smooth muscle } \\
\text { actin (SMA) }\end{array}$ & ab15267 & Smooth muscle & no & $10 \mathrm{~min}$ & $\begin{array}{l}\text { Human } \\
\text { colon }\end{array}$ & rabbit & $1 / 150$ & $\begin{array}{l}\text { abcam; } \\
\text { USA }\end{array}$ \\
\hline
\end{tabular}

\section{Supporting information 2 Supporting information: Movie File of the pelvic floor of fetus B.}

Code: the centro-levator area (centro) is in light green; the infra-levator (infra) in light blue; the levator ani muscle in orange; the external anal sphincter in dark blue; the external urethral sphincter in light purple; the prostate in dark red; the rectum in beige; and the internal urethral sphincter in dark purple; the bulbospongiosus muscle in pink; nerve to levator ani in green; the pudendal nerve in blue; the inferior hypogastric plexus in yellow.

\section{Supporting information 3:}

Computer-assisted anatomical dissection (CAAD) of the pelvic structure in a 21-week-old male fetus.

A to C: Structures are revealed on right lateral views.

A: 
The internal US (in dark purple) surrounds the urethra (yellow) down to the urethral bulb The external US (in semi-transparent light purple) surrounds the internal US.

Appearance of the bulbospongiosus muscle (BSM, pink)

Appearance of the smooth muscle middle compartment (SMMC) with the core (or rectourethral muscle, light green), the endolevator area (or medial part of the levator ani muscle dark pink), the infralevator area (or deep transverse perineal muscle, light blue).

B:

The rectum is surrounded by the SMMC

C:

Levator ani muscle (LAM, orange) and external anal sphincter (EAS, dark blue)

D: Oblique view. Caudally the external US opens in its posterior aspect.

E: Superior view.

Smooth muscle cells from smooth muscle central (in green) compartment attached to the internal US.

This 3D reconstruction shows the relation of the US to other pelvic structures.

Color code: Urethra (yellow), prostate (dark red), internal urethral sphincter (dark purple), external urethral sphincter (dark purple), levator ani muscle (LAM, orange), rectum (beige), smooth muscle cells compartment (core or rectourethral muscle in green, infralevator area or deep transverse perineal muscle in light blue and endolevator area or medial part of the levator ani muscle in light purple), external anal sphincter (EAS, dark blue).

\section{Supporting information 4: Transverse sections of a 23-week-old male fetus scanned at an} optical resolution of $4800 \mathrm{dpi}$ at the levels of caudal membranous urethra (A, B, B1, B2).

Sections (A) is stained with Masson's trichrome.

Sections (B) and (B1) are stained with anti-S100 antibody.

Sections (B2) is stained with anti-PMP22 antibody.

(B1, B2) are magnified views from rectangle in (B) with anti- S100 and anti-PMP22 staining.

The pudendal nerve is shown with green arrowhead.

The pudendal nerve gives perineal nerve fibers that curve medially to the EUS at the level of the wings. These nerves are somatic (positive anti-PMP22) (black arrowhead in (B2).

Color code : External urethral sphincter (EUS, light purple), internal urethral sphincter (IUS, dark purple), levator ani muscle (LAM, orange), rectum (beige), smooth muscle cells of the middle 
compartment (the core or rectourethral muscle in green, endolevator area or medial part of the levator ani muscle in pink and infra levator area or deep transverse perineal muscle, light blue), and cavernous corpus $(\mathrm{CC}$, red). 


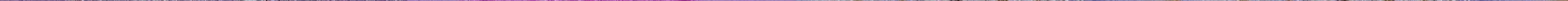




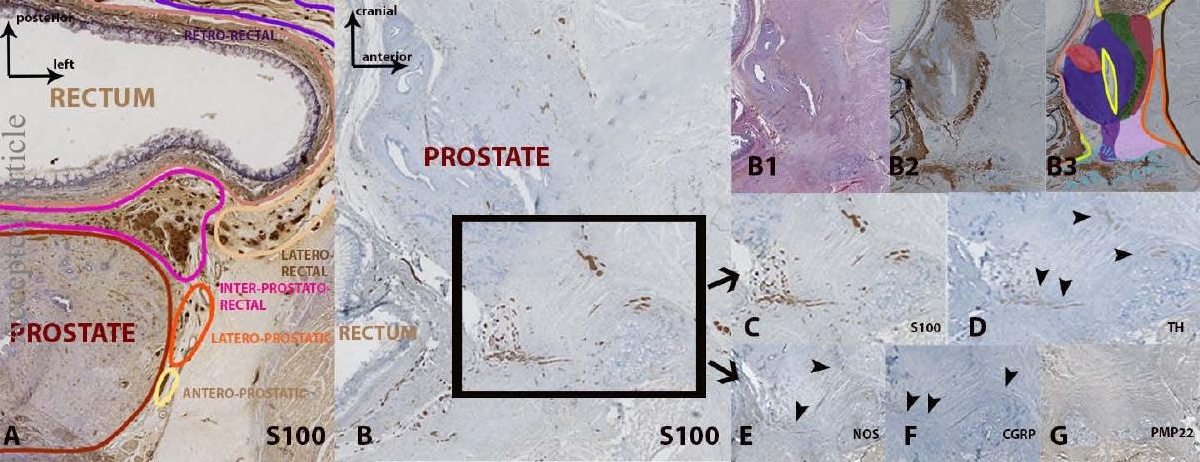




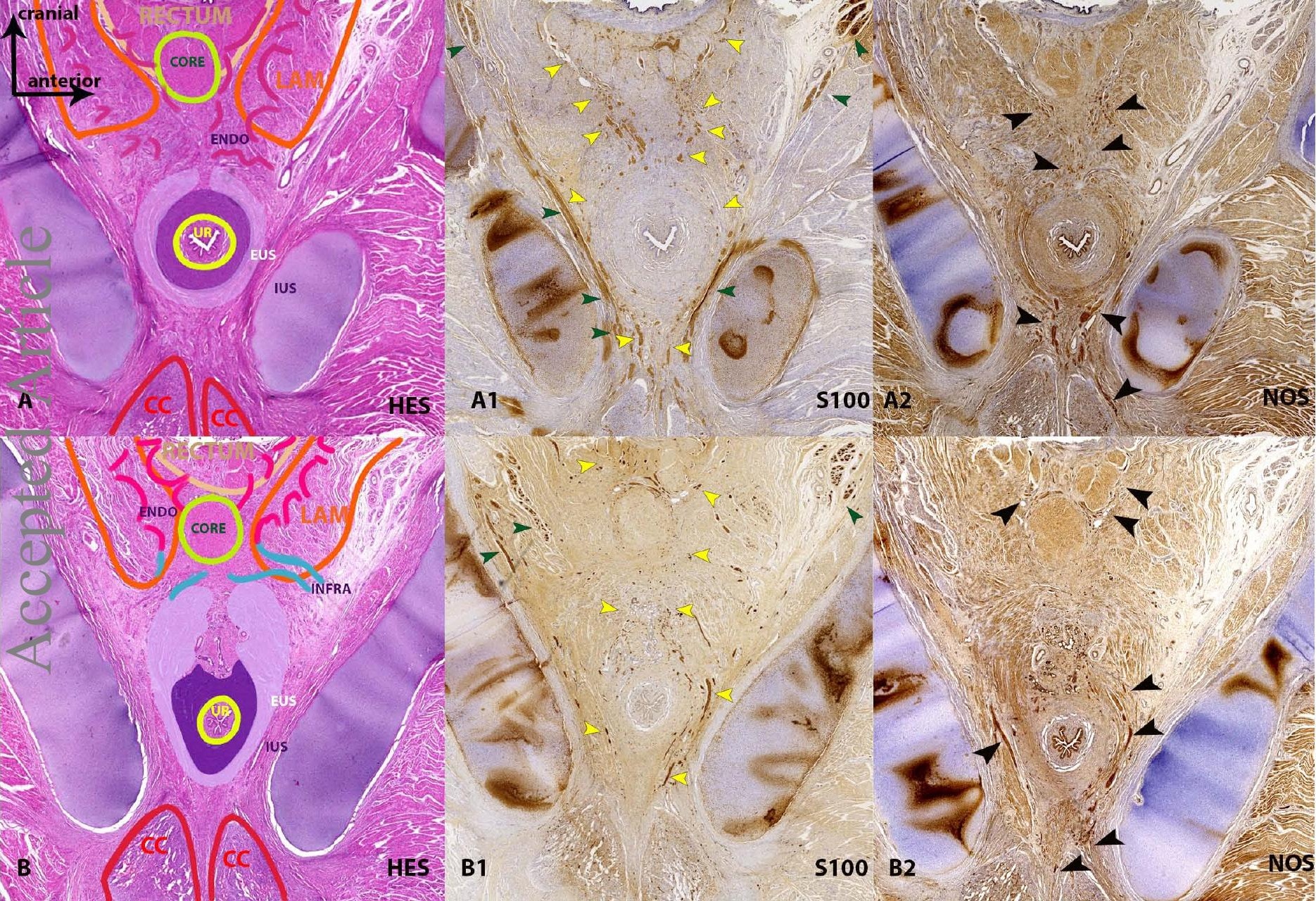




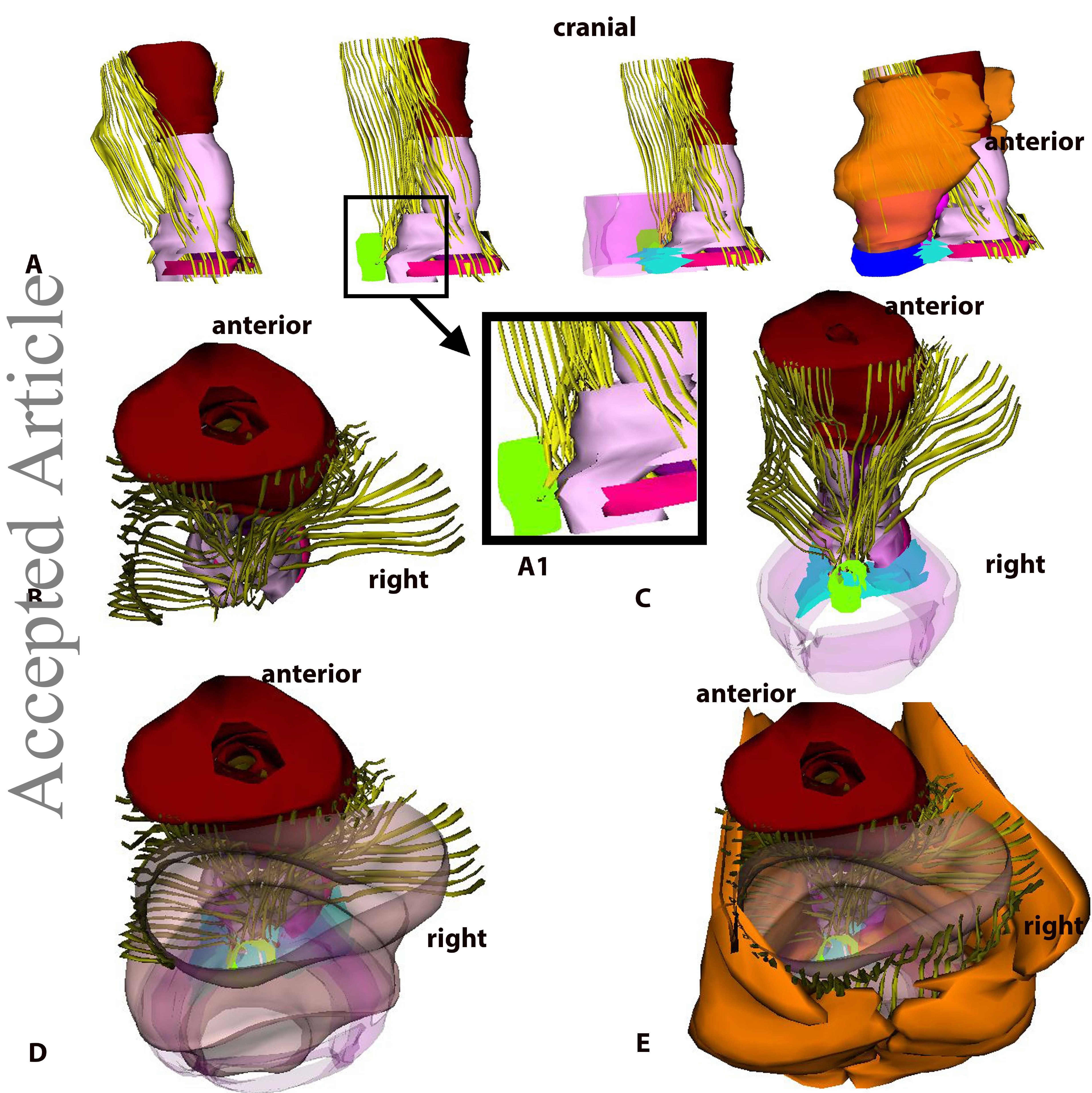




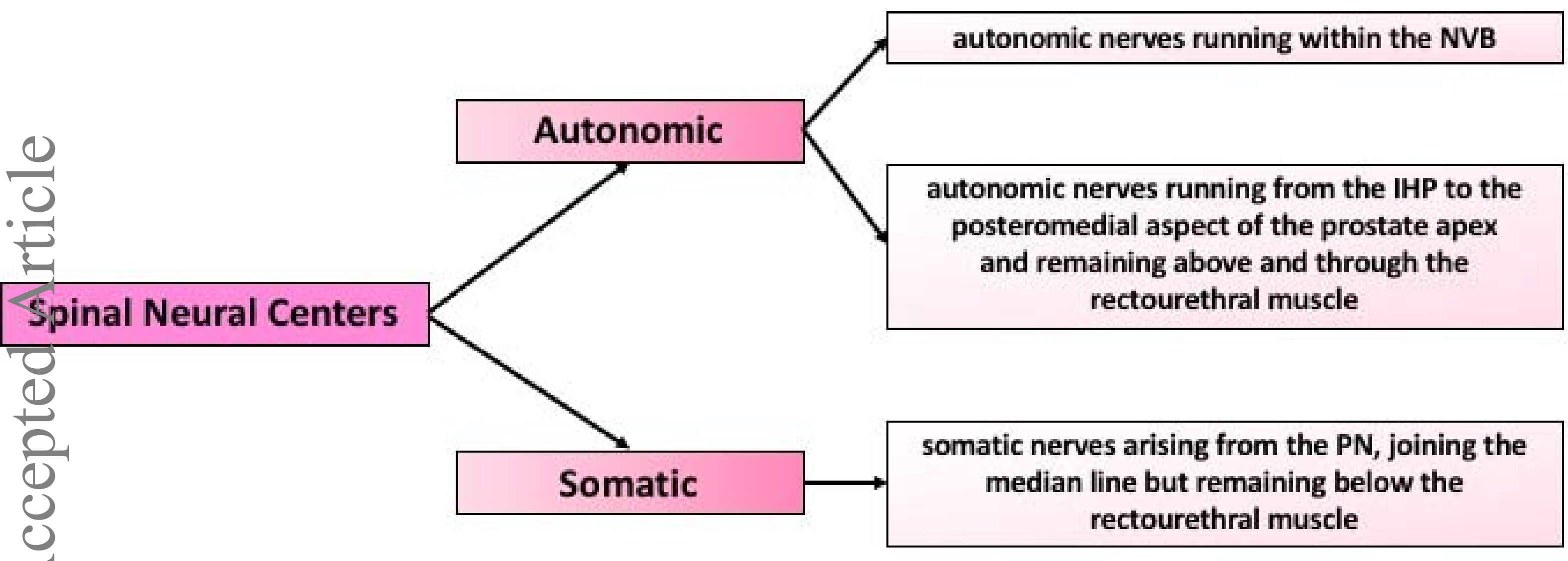

